\title{
In Vivo Modulation of Sensory Input to the Olfactory Bulb by Tonic and Activity-Dependent Presynaptic Inhibition of Receptor Neurons
}

\author{
Nicolás Pírez and Matt Wachowiak \\ Department of Biology, Boston University, Boston, Massachusetts 02215
}

\begin{abstract}
The first reorganization of odor representations in the nervous system occurs at the synapse between olfactory receptor neurons and second-order neurons in olfactory bulb glomeruli. Signal transmission at this synapse is modulated presynaptically by several mechanisms, a major one being mediated by $\mathrm{GABA}_{\mathrm{B}}$ receptors, which suppress presynaptic calcium influx and subsequent transmitter release from the receptor neuron terminal. Here, we imaged stimulus-evoked calcium influx into the receptor neuron terminal in anesthetized mice and used odorant and electrical stimulation combined with in vivo pharmacology to characterize the functional determinants of $\mathrm{GABA}_{\mathrm{B}}$-mediated presynaptic inhibition and to test hypotheses on the role of this inhibition in olfactory processing. As expected from previous studies, blocking presynaptic $\mathrm{GABA}_{\mathrm{B}}$ receptors in vivo increased odorant-evoked presynaptic calcium signals, confirming that $\mathrm{GABA}_{\mathrm{B}}$-mediated inhibition modulates the strength of receptor inputs. Surprisingly, we found that the strength of this inhibition was affected little by the nature of the input, being independent of the spatial distribution of activated glomeruli, independent of the sniff frequency used to sample the odorant, and similar for weak and strong odorant-evoked inputs. Instead, we found that tonic inhibition was a major determinant of receptor input strength; this tonic inhibition in turn was dependent on glutamatergic transmission from second-order neurons in the glomerular layer. Thus, rather than adaptively shaping odor representations in an activity-dependent manner, a primary role of presynaptic inhibition in vivo may be to modulate the magnitude of sensory input to the brain as a function of behavioral state.
\end{abstract}

Key words: calcium; GABAergic modulation; olfactory bulb; optical imaging; presynaptic regulation; sensory neurons

\section{Introduction}

At the first synapse in the olfactory pathway, olfactory receptor neurons (ORNs) make excitatory connections with second-order interneurons. The connection between ORNs and second-order neurons is massively convergent, with several thousand ORNs targeting many fewer second-order neurons within a small (50$100 \mu \mathrm{m}$ ), anatomically discrete neuropil called a glomerulus. The first step in central olfactory processing occurs on the presynaptic side of this synapse, in which presynaptic inhibition regulates signal transmission from ORNs to second-order neurons (Wachowiak and Cohen, 1999; Aroniadou-Anderjaska et al., 2000; Ennis et al., 2001; McGann et al., 2005; Vucinic et al., 2005; Wachowiak et al., 2005; Olsen and Wilson, 2008). Here, inhibitory interneurons can suppress the release of neurotransmitter from ORNs by downregulating action potential-evoked calcium influx into the presynaptic terminal (Wachowiak and Cohen, 1999; Wachowiak et al., 2005) and possibly via additional cellular mechanisms (Murphy and Isaacson, 2003). Thus, presynaptic

Received Feb. 21, 2008; revised May 6, 2008; accepted May 7, 2008.

This work was funded by National Institutes of Health Award DC6441. We thank M. Shipley, J. McGann, D. Wesson, R. Carey, and M.-C. Cheung for helpful discussions and comments on this manuscript.

Correspondence should be addressed to Dr. Matt Wachowiak, Department of Biology, Boston University, 5 Cummington Street, Boston, MA 02215. E-mail: dmattw@bu.edu.

DOI:10.1523/JNEUROSCI.0793-08.2008

Copyright $\odot 2008$ Society for Neuroscience $\quad$ 0270-6474/08/286360-12\$15.00/0 inhibition can strongly modulate the strength of primary sensory input to the CNS. Modulation of signal transmission at this synapse has the potential to profoundly shape odor coding in the brain.

Basic functional properties of ORN presynaptic inhibition have been well characterized, in particular those mediated by GABAergic inhibition. In the mammalian olfactory bulb (OB), GABA released from periglomerular interneurons suppresses ORN input via $\mathrm{GABA}_{\mathrm{B}}$ receptors expressed on the ORN terminal (Nickell et al., 1994; Bonino et al., 1999; Kratskin et al., 2006), and, in $\mathrm{OB}$ slice preparations, this transmitter pathway appears to be the major mediator of stimulus-evoked presynaptic inhibition (Aroniadou-Anderjaska et al., 2000; McGann et al., 2005; Wachowiak et al., 2005). In vivo, $\mathrm{GABA}_{\mathrm{B}}$-mediated inhibition modulates the strength of odorant-evoked inputs to the OB (McGann et al., 2005), but many of the functional determinants of this inhibition remain unclear. For example, presynaptic "center-surround" inhibition between glomeruli may serve to sharpen odorant representations, but two previous studies addressing this question in vivo have yielded contradictory results (McGann et al., 2005; Vucinic et al., 2005). Likewise, previous studies in $\mathrm{OB}$ slices asking whether tonic $\mathrm{GABA}_{\mathrm{B}}$-mediated inhibition regulates ORN inputs have yielded differing results (Aroniadou-Anderjaska et al., 2000; McGann et al., 2005; Wachowiak et al., 2005); whether tonic inhibition regulates ORN 
inputs in vivo has not been addressed. Other predictions of the functional role of presynaptic inhibition in odor coding include rapid adaptive gain control, modulating the strength of sensory input as a function of sniffing frequency, and modulating input sensitivity as a function of behavioral state (Nickell et al., 1994; McGann et al., 2005; Wachowiak and Shipley, 2006). These predictions derive from experiments in $\mathrm{OB}$ slice preparations but have not been tested in vivo.

In this study, we tested these predictions by characterizing the functional determinants underlying the presynaptic regulation of ORN input to the mouse OB. We focused in particular on presynaptic inhibition in the context of inputs driven by sniffing, which determines the temporal dynamics of odorant-evoked input to the $\mathrm{OB}$. We found that $\mathrm{GABA}_{\mathrm{B}}$-mediated regulation of the strength of receptor input to the $\mathrm{OB}$ in vivo is independent of the spatial distribution of activated glomeruli, independent of the sniff frequency used to sample the odorant, and of similar magnitude for weak and strong ORN inputs. We also found that tonic presynaptic inhibition plays a larger than expected role in regulating the strength of ORN inputs. Thus, we hypothesize that, rather than adaptively shaping odor representations in an activity-dependent manner, a primary role of presynaptic inhibition during natural odor sampling in vivo may be to modulate the magnitude of sensory input to the OB depending on the behavioral state of the animal.

\section{Materials and Methods}

Subjects. Experiments were performed on C57BL/6 mice of both sexes (Charles River Laboratories) ranging from 5 to 21 weeks old $(7.5 \pm 0.3$ weeks). All animal procedures were approved by the Boston University Institutional Animal Care and Use Committee and followed National Institutes of Health guidelines for care and use of laboratory animals.

Calcium dye loading and in vivo optical imaging. ORNs were loaded in vivo with $4 \%$ Calcium Green-1 dextran, $10 \mathrm{kDa}$ (Invitrogen), as previously described (Wachowiak and Cohen, 2001; Wachowiak et al., 2005). In vivo imaging was performed 3-7 d after the loading procedure. For most experiments, mice were anesthetized with pentobarbital $(50 \mathrm{mg} /$ $\mathrm{kg})$. In some experiments, mice were anesthetized with isoflurane (1-2\% in $\left.\mathrm{O}_{2}\right)$. Dexamethasone $(2 \mathrm{mg} / \mathrm{kg})$ was administered to reduce brain swelling. Body temperature was maintained at $37^{\circ} \mathrm{C}$, and heart rate was maintained at $\sim 400$ beats per minute. In most experiments, a double tracheotomy was performed, and an artificial sniff paradigm was used to approximate naturalistic odor sampling behavior at precise and reproducible frequencies (Wachowiak and Cohen, 2001; Spors et al., 2006). In preparation for imaging, mice were secured in a custom head holder, and the bone and dura overlying one or both OBs was removed to allow application of pharmacological agents and placement of a stimulating electrode (described below). Optical signals were acquired from the dorsal surface of one OB using wide-field epifluorescence as described previously (Wachowiak and Cohen, 2001; Bozza et al., 2004; Spors et al., 2006), using an Olympus BX51 illumination turret and a $150 \mathrm{~W}$ xenon arc lamp (Opti-Quip) attenuated to $25 \%$ full intensity. A $10 \times$ long working-distance water-immersion objective ( 0.3 numerical aperture) was used in most experiments, which allowed most of the dorsal $O B$ to be visualized $(1.7 \times 1.7 \mathrm{~mm}$ field of view). To image Calcium Green-1 fluorescence, the following filter set was used: exciter, $500 \pm 25 \mathrm{~nm}$; dichroic, 525 long pass; emitter, 530 long pass. Optical signals were recorded and digitized at 14 bit resolution using a back-illuminated CCD camera (NeuroCCD, SM-256; RedShirtImaging). Odorant-evoked signals were acquired at $256 \times 256$ pixel resolution and a frame rate of 25 $\mathrm{Hz}$; olfactory nerve $(\mathrm{ON})$ shock-evoked signals were acquired at $128 \times$ 128 pixel resolution and frame rate of $125 \mathrm{~Hz}$. Data acquisition was performed with Neuroplex software (RedShirtImaging).

Pharmacological agents were applied by manually replacing the standard mouse Ringer's solution (Bozza et al., 2004) with Ringer's solution containing the drug and waiting at least 5 min before imaging post- drug responses. (3-Aminopropyl) (diethoxymethyl) phosphinic acid (CGP35348) was obtained from Tocris Cookson; 2,3-dihydroxy-6nitro-1,2,3,4-tetrahydrobenzo[f] quinoxaline-7sulfonamide (NBQX) and tetrodotoxin (TTX) were obtained from Sigma. For the vehicle control experiments, control Ringer's solution were applied instead of the drug containing Ringer's solution.

Odorant and electrical stimulation. Odorants were presented as dilutions from saturated vapor in cleaned, desiccated air using a custom olfactometer under computer control as described previously (Bozza et al., 2004; Verhagen et al., 2007). Odorant presentation was typically for $4 \mathrm{~s}$. All odorants were obtained at $95-99 \%$ purity from Sigma and stored under nitrogen. The binary mixture experiments used the following odorant pairs ( $n$ values given in parentheses): methyl valerate (MV)/ butyl acetate (BA) (3), methyl valerate/isoamyl acetate (3), methyl valerate/heptanone (2), ethyl butyrate/isoamyl acetate (1), ethyl butyrate/ heptanone (1), ethyl butyrate/butyl acetate (1), and methyl benzoate/ heptanone (1).

For experiments involving electrical stimulation of the $\mathrm{ON}$ in vivo, stimuli were applied through a concentric bipolar electrode with tip diameter of $25 \mu \mathrm{m}$ (FHC). The electrode was placed on the olfactory nerve layer in the anteromedial quadrant on the dorsal OB. Brief $(100 \mu \mathrm{s})$ constant-current stimuli $(600-950 \mu \mathrm{A})$ were delivered through an Isoflex stimulus isolation unit (A.M.P.I.) triggered by a Master-8 (A.M.P.I.) or through a linear constant-current stimulus isolator unit (Neurolog System, NL800A; Digitimer) under the control of custom software written in LabView (National Instruments).

Data analysis. Measurement and analysis of evoked responses in individual glomeruli was performed using commercial (Neuroplex) and custom software, as described previously (McGann et al., 2005). Briefly, optical signal foci were identified as glomeruli by visual inspection; to be included as a glomerulus, signals had to appear as approximately circular foci between 50 and $150 \mu \mathrm{m}$ in diameter. Diffuse signals of larger dimension were not chosen. For analysis, pixels overlying the center of each signal focus (defined below) were spatially averaged and normalized to its resting fluorescence, yielding units of $\Delta F / F$. The signal-to-noise ratio of the data were improved by averaging several trials (minimum of three but typically four to six). Responses were only included for analysis if the mean response amplitude of a glomerulus was greater than 3 SEMs across trials. This selection criterion eliminated only a few glomeruli with weak and noisy signals and did not bias the selection of glomeruli toward only strongly activated ones (see Fig. $2 \mathrm{~A}, 3 \mathrm{~Hz}$ only). Response amplitudes for glomeruli included for analysis ranged from 0.47 to $42.5 \% \Delta F / F$. Odorant-evoked response amplitudes were measured as the temporal average of the $\Delta F / F$ signal in eight frames ( $320 \mathrm{~ms}$ ) centered on the peak of the response, relative to the signal just before response onset. Shockevoked response amplitudes were the temporal average of two to four frames $(16-32 \mathrm{~ms})$ centered at the response peak.

For comparison of spatial maps of odorant-evoked input, correlation coefficients (Pearson's $r$ ) were computed from the set of all responsive glomeruli in a given preparation. Analysis of center-surround inhibition was performed as described by Vucinic et al. (2005). The "center" of a glomerulus was defined as a circular area with an $85 \mu \mathrm{m}$ diameter centered on the signal focus. The "surround" of a glomerulus was selected as a $100-\mu \mathrm{m}$-thick annular region around the center, with the innermost extent of the surround set at $100 \mu \mathrm{m}$ from the center (e.g., $100 \leq r \geq 200$ $\mu \mathrm{m}$ ) (see Fig. 3C). Similar results were obtained when the analysis was done using a surround region of the same size but $200 \mu \mathrm{m}$ from the glomerulus center $(200 \leq r \geq 300 \mu \mathrm{m})$. Fluorescence from all pixels within this surround region was spatially averaged and measured as $\Delta F / F$. For analysis of the electrical stimulation experiments, glomeruli were selected in the same manner as for odorant-evoked responses. Signal-to-noise ratios were somewhat lower in these experiments because of the higher frame rate. For display in the figures (see Figs. 5, 7), these response maps were spatially filtered using a $5 \times 5$ pixel Gaussian kernel and maps displayed as raw $\Delta F$ to enhance the visibility of glomeruli. To analyze the effect of pharmacological agents on the odorant- and shock-evoked signals, the average of the last four to eight trials before drug application was compared with the average of first four to eight trials after drug application. 
Statistical analyses were performed with StatView (SAS Institute) or Matlab (MathWorks).

\section{Results}

A major goal of these experiments was to understand how presynaptic inhibition at the ORN terminal shapes sensory input to the OB during naturalistic odor sampling behavior (i.e., sniffing). To achieve the temporal resolution necessary to address this question, we used calcium-sensitive dyes loaded into ORNs to monitor odorant-evoked activity and its modulation at the presynaptic terminal (Wachowiak et al., 2005). Suppression of calcium influx into the ORN terminal is a primary mechanism mediating presynaptic inhibition in OB slices (Wachowiak and Cohen, 1999; Wachowiak et al., 2005) and in vivo (McGann et al., 2005; Vucinic et al., 2005); synaptopHluorin $(\mathrm{SpH})$, a more direct optical indicator of transmitter release from ORN terminals, yields insufficient temporal resolution to analyze inputs evoked by individual sniffs in vivo (Bozza et al., 2004; McGann et al., 2005). We also chose to focus exclusively on $\mathrm{GABA}_{\mathrm{B}}$-mediated presynaptic inhibition in this study. The experiments were primarily informed by predictions arising from previous studies in OB slice preparations (Wachowiak and Cohen, 1999; Aroniadou-Anderjaska et al., 2000; McGann et al., 2005; Murphy et al., 2005; Wachowiak et al., 2005), and, in these studies, $\mathrm{GABA}_{\mathrm{B}}$ receptor antagonists relieve nearly all synaptically mediated presynaptic inhibition, suggesting that this transmitter pathway is a primary regulator of sensory input. Although other neurotransmitter pathways may play a role in presynaptic inhibition, for example, dopamine (Hsia et al., 1999; Ennis et al., 2001), preliminary work suggested that their role in regulating odorant-evoked input in vivo was less prominent and more complex than for $\mathrm{GABA}_{\mathrm{B}}$-mediated inhibition (data not shown).

\section{Determinants of $\mathrm{GABA}_{B}$-mediated regulation of receptor input to the $\mathrm{OB}$ in vivo}

We first confirmed that odorant-evoked inputs to OB glomeruli are modulated at the level of calcium influx into the ORN termi$\mathrm{nal}$, as reported in a previous study in juvenile mice (14-29 d old) (Vucinic et al., 2005). As expected, we found similar effects in adult mice (5-21 weeks old). Figure 1 shows examples of odorant-evoked response maps and traces from individual glomeruli before and after applying the $\mathrm{GABA}_{\mathrm{B}}$ antagonist CGP35348 (1 mM) to the dorsal surface of the OB. We initially focused on responses during artificial sniffing of odorant at a frequency of $3 \mathrm{~Hz}$ to facilitate comparison with previous work (McGann et al., 2005; Vucinic et al., 2005). GABA $_{B}$ receptor blockade caused a significant increase in the amplitude of the odorant-evoked presynaptic calcium signal when measured after 2 s of odorant exposure [132 $\pm 3.4 \%$ (mean \pm SEM) of predrug values; one-group $t$ test $p<0.0001 ; 70$ glomeruli, 6 animals]. Application of control mouse Ringer's solution had no significant effect $(99 \pm 2.3 \%$ of initial values, one-group $t$ test, $p=$ $0.855 ; 51$ glomeruli, 5 animals). The effect of CGP35348 reversed very slowly, if at all, and we did not attempt to obtain complete reversals in vivo.

One hypothesized role of presynaptic inhibition is as a rapid, adaptive gain control mechanism in which strong odorantevoked inputs are preferentially suppressed (Nickell et al., 1994; McGann et al., 2005; Wachowiak and Shipley, 2006). To test this hypothesis, we used the increase in the odorant-evoked signal after $\mathrm{GABA}_{\mathrm{B}}$ receptor blockade as a measure of the strength of presynaptic inhibition and used the amplitude of the predrug odorant-evoked response as a measure of input strength. For this and subsequent analyses, we included all glomeruli showing a mean response amplitude more than three times their SEM across trials (see Materials and Methods). This cutoff excluded very few glomeruli and included glomeruli with responses of as little as $10 \%$ of the strongest-activated glomeruli (Fig. $2 \mathrm{~A}$ ). We predicted that preferential suppression of strong inputs should be apparent as a greater effect of CGP35348 for higher initial response magnitudes. We tested this by normalizing responses to the maximal response amplitude in each preparation, binning each response into one of five amplitude levels (Fig. $2 B$ ) and testing for differential effects of $\mathrm{GABA}_{\mathrm{B}}$ receptor blockade across bins using ANOVA. This analysis showed no effect of response magnitude on the effect of $\mathrm{GABA}_{\mathrm{B}}$ receptor blockade (ANOVA, $\left.F_{(4,65)}=0.759, p=0.5558\right)$. This analysis also suggests that saturation of the high-affinity calcium-sensitive dye is not a major limitation in detecting modulation of calcium influx in this data set, because dye saturation would be expected to cause a smaller increase in calcium signal for stronger ORN inputs.

Presynaptic inhibition has also been hypothesized to preferentially suppress ORN inputs during high-frequency $(>4 \mathrm{~Hz})$ exploratory sniffing (Aroniadou-Anderjaska et al., 1999; Wachowiak and Shipley, 2006), because, in OB slices, presynaptic inhibition is maximal 50-200 ms after a conditioning ON shock 
A
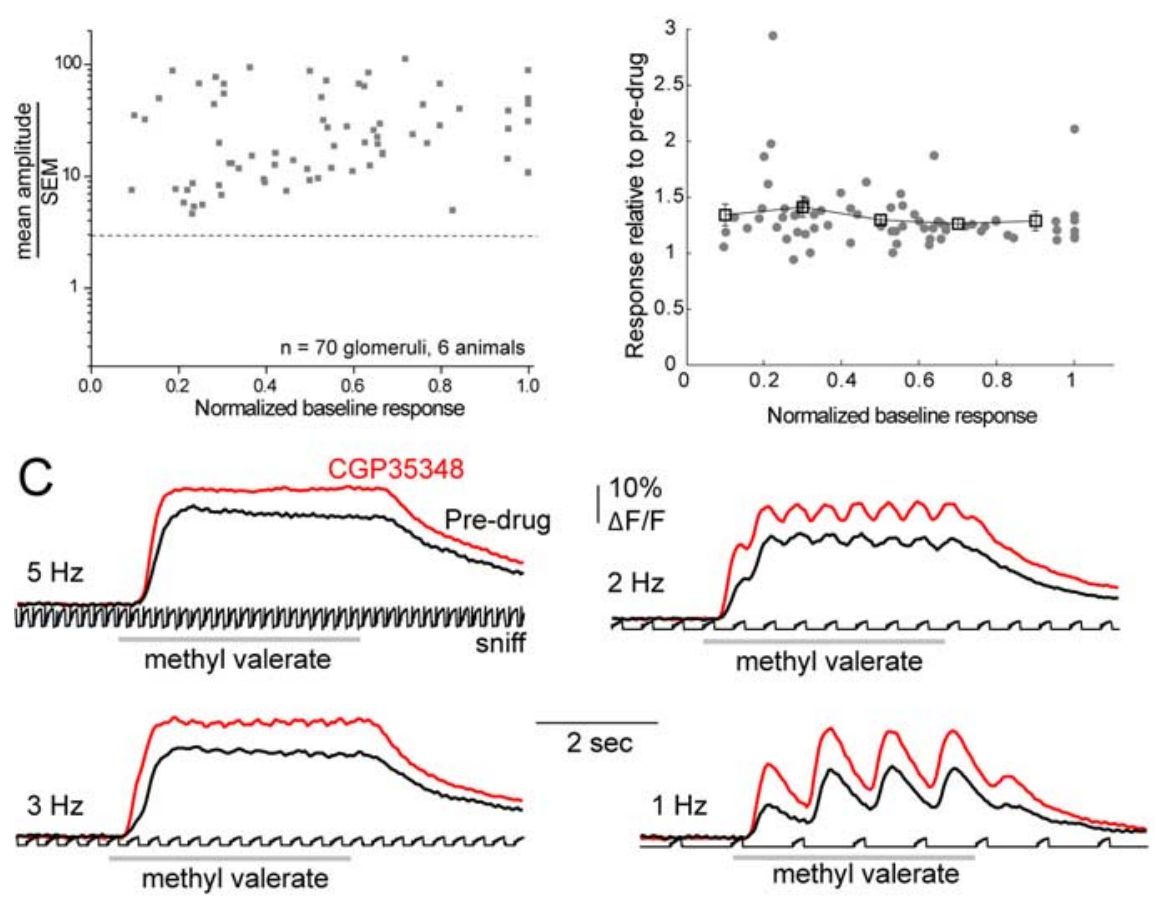

D

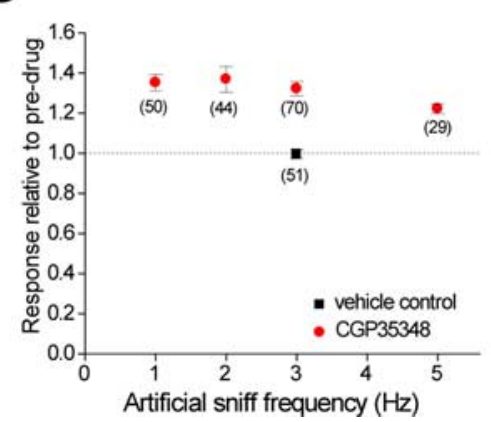

B
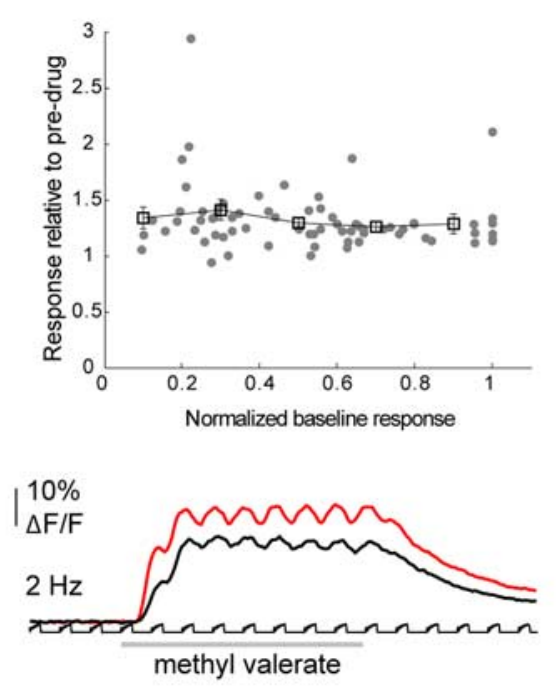

E

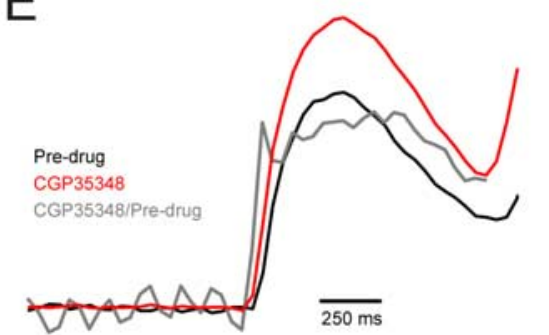

Figure 2. No effect of input magnitude or sniff frequency on the strength of $\mathrm{GABA}_{\mathrm{B}}$-mediated presynaptic inhibition. $\boldsymbol{A}$, Signal-to-noise ratios (mean response amplitude/SEM; see Materials and Methods) for the glomeruli used in the analysis in $\boldsymbol{B}$. Dotted line indicates the cutoff ratio of 3 used as a criterion for including glomeruli in the analysis. Signal-to-noise ratios were above the cutoff even for glomeruli that were at the low end of the range of response amplitudes (i.e., were weakly activated). $\boldsymbol{B}$, Increase in odorant-evoked response amplitude after CGP35348 (1 mM) application as a function of normalized predrug response amplitude for individual glomeruli. Each filled gray circle indicates one glomerulus. Larger open squares indicate mean \pm SEM after binning glomeruli into five response levels. The effect of CGP35348 is similar across bins (for statistical tests, see Results). Data are from $3 \mathrm{~Hz}$ sniffing experiments only and are measured after $2 \mathrm{~s}$ of odorant stimulation. $\boldsymbol{C}$, Traces showing responses of one glomerulus to methyl valerate ( $0.75 \%$ s.v.) sampled at different artificial sniff frequencies before and after CGP35348 application. All traces are from the same glomerulus. D, Summary data showing the change in response amplitude in CGP35348 at frequencies of $1,2,3$, and $5 \mathrm{~Hz}$. Responses are measured after $2 \mathrm{~s}$ of odorant stimulation. Numbers in parentheses indicate number of glomeruli for each measurement. $\boldsymbol{E}$, Traces showing the mean response to the first artificial sniff of odorant ( $17 \mathrm{glomeruli,} 3$ animals) before drug application (black) and in the presence of CGP35348 (red). Gray trace shows the CGP35348/predrug ratio, calculated by dividing each pair of predrug and drug traces and then averaging these ratiometric traces. The effect of CGP35348 is apparent as soon as responses are detectable and reaches peak magnitude in $50 \mathrm{~ms}$ or less (the ratiometric trace appears to start just before signal onset, but this corresponds to a single imaged frame and likely reflects cases in which the response becomes detectable one frame earlier in the presence of (GP35348 attributable to reduced inhibition). Response traces are normalized to the same arbitrary value; ratiometric trace is scaled for optimal visualization of time course.

and decays over the next $600-800 \mathrm{~ms}$ (Aroniadou-Anderjaska et al., 2000; McGann et al., 2005; Wachowiak et al., 2005). We thus asked whether the magnitude of $\mathrm{GABA}_{B}$-mediated inhibition was different at different sniff frequencies. We imaged odorantevoked responses at frequencies of 1, 2, 3, and $5 \mathrm{~Hz}$ (Fig. 2C). Because sniff frequencies above $3 \mathrm{~Hz}$ evoke primarily tonic sig- nals with no responses evoked by individual sniffs (Spors et al., 2006; Verhagen et al., 2007), we did not test frequencies above $5 \mathrm{~Hz}$. $\mathrm{GABA}_{\mathrm{B}}$ receptor blockade revealed significant presynaptic inhibition at all sniff frequencies (Fig. 2D) (ANOVA, $\left.F_{(3,378)}=4.383, p=0.037\right)$, with the effect of CGP35348 showing similar increases in response amplitude after $\sim 2 \mathrm{~s}$ of odorant stimulation at each frequency (Figs. $2 C, D)$. ANOVA revealed no significant effect of sniff frequency on the effect of CGP35348 $(1 \mathrm{~Hz}, 135 \pm 4.1 \% ; 2 \mathrm{~Hz}, 137 \pm$ 6.4\%; $3 \mathrm{~Hz}, 132 \pm 3.4 \% ; 5 \mathrm{~Hz}, 122 \pm$ $2.5 \%)\left(\right.$ ANOVA, $F_{(3,378)}=1.507, p=$ 0.2123 ). Because the effect of increased sniff frequency could take several seconds to develop or could saturate after a short time, we also tested for frequencydependent effects of CGP35348 after 1 and $4 \mathrm{~s}$ of odorant exposure. This analysis again yielded no significant effects of sniff frequency ( $1 \mathrm{~s}:$ ANOVA, $F_{(3,378)}=2.344$, $p=0.0727 ; 4$ s: ANOVA, $F_{(3,378)}=1.241$, $p=0.2945)$.

We also measured effects of CGP35348 on responses evoked by the first sniff of odorant, before frequency-dependent effects could occur (1 Hz only). Here, response amplitudes were significantly increased in the presence of CGP35348 (141 $\pm 4.5 \%$ of predrug amplitudes; one-group $t$ test, $p<$ 0.0001; 50 glomeruli, 4 animals); this effect was slightly larger than the effect of CGP35348 on responses after $2 \mathrm{~s}$ of $3 \mathrm{~Hz}$ sniffing ( $132 \pm 3.4 \%$ of predrug amplitude) (unpaired $t$ test, $p=0.1174 ; 120$ glomeruli, 7 animals). Finally, we investigated the effect of $\mathrm{GABA}_{\mathrm{B}}$ receptor blockade on the kinetics of the response for the first sniff of odorant. To visualize this, the trace of the first-sniff response in CGP35348 was divided by the trace obtained before drug to yield a trace showing the effect of CGP35348 throughout the time course of the response. We used only a subset of the initial dataset for this analysis (17 glomeruli, 3 animals, $1 \mathrm{~Hz}$ ) to minimize noise in the ratiometric traces. Examination of the mean of the predrug, postdrug, and ratiometric traces revealed that the effect of CGP 35348 on response amplitude is present as soon as any odorant-evoked signal is detectable and reaches maximal effect within $50 \mathrm{~ms}$ of response onset (Fig. 2E).

\section{Intraglomerular versus interglomerular} presynaptic inhibition of ORN inputs

A third proposed role for presynaptic inhibition is to sharpen maps of receptor input to glomeruli via interglomerular "centersurround" inhibition (Vucinic et al., 2005). Evidence in support of interglomerular presynaptic inhibition in vivo is mixed, however (McGann et al., 2005; Vucinic et al., 2005). We addressed this question with three experiments. First, we compared spatial 
patterns of odorant-evoked calcium signals (i.e., "maps") before and after application of CGP35348. Figure $3 A$ shows the same data as in Figure $1 A$ but with each response map normalized to its own maximum. In this example, the relative response maps before and after CGP35348 application are nearly identical. Overall, response maps evoked by the same odorant and concentration before and after CGP35348 were highly correlated (Pearson's $r=0.88 \pm 0.034)$; their correlation coefficient was not different from the correlation of response maps evoked by repeated odorant presentations (Pearson's $r=0.87 \pm 0.041$ ) (paired $t$ test, $p=$ $0.3739 ; 3 \mathrm{~Hz}$ sniffing data only; 6 animals). We also compared the relative distributions of odorant-evoked response amplitudes before and after $\mathrm{GABA}_{\mathrm{B}}$ receptor blockade (Fig. 3B) and found no significant effect (Kolmogorov-Smirnov test, $p=0.9505 ; 70$ glomeruli, 6 animals).

Second, we replicated the analysis of Vucinic et al. (2005), which tests for center-surround inhibition between glomeruli by asking whether CGP35348 preferentially increases responses of glomeruli located in the surrounds of more strongly activated glomeruli. The analysis, shown in Figure $3 C(100 \leq r \geq 200 \mu \mathrm{m})$, plots the ratio of the drug-induced change in response amplitude for a glomerulus to that of its surround against the ratio of the predrug response amplitude of that glomerulus to its surround. Preferential effects on weaker glomeruli in the surround (consistent with a center-surround inhibitory organization) should result in a positive relationship between these ratios, because strongly activated glomeruli would presumably inhibit those surrounding them, and blocking this inhibition would result in larger CGP35348 effects in these inhibited, surrounding glomeruli than in the strongly activated center glomerulus ( $\mathrm{Vu}$ cinic et al., 2005). To test this, we fitted the data to the function

$$
y=1+\operatorname{alog}\left(\frac{x}{b}\right)
$$

(Vucinic et al., 2005); when plotted on a

log-linear scale, no change in either relative or absolute response amplitudes would result in data distributed along the horizontal $(a=0)$. We found that both vehicle and CGP35348 experiments yielded fit slopes that were not significantly different from 0 (Fig. $3 C$ ), with values of $a=0.006 \pm 0.102$ (95\% confidence interval) for vehicle and $a=0.0001 \pm 0.0943$ for CGP35348. We obtained identical results using a surround area of the same thickness but with innermost extent located $200 \mu \mathrm{m}$ from the glomerulus center (200 $\leq r \geq 300 \mu \mathrm{m})$, obtaining fit slopes of $a=0.002 \pm 0.083$ for vehicle and $a=0.008 \pm 0.085$ for CGP35348 (data not shown).
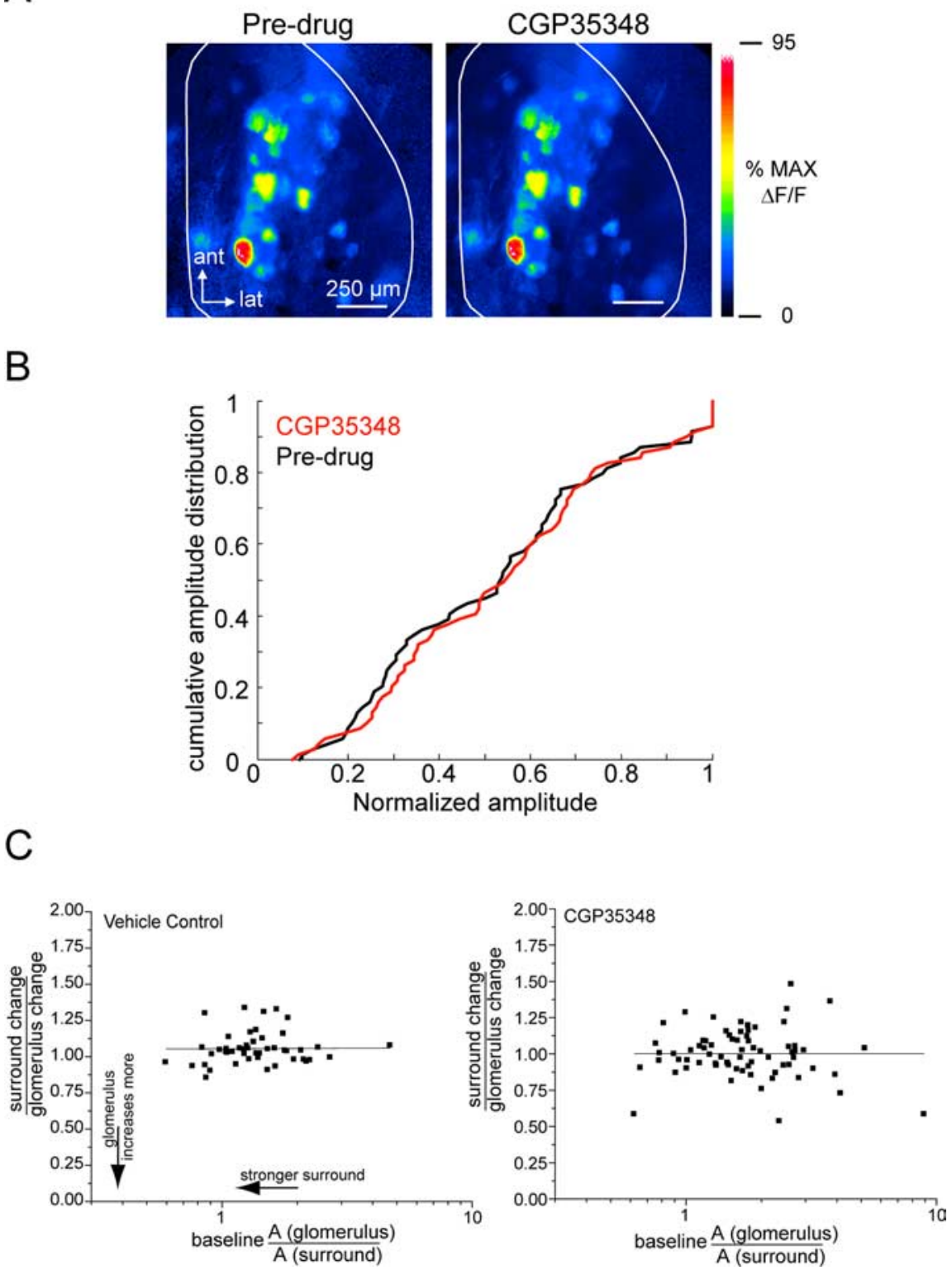

Figure 3. No evidence for $\mathrm{GABA}_{B}$-mediated center-surround inhibition of receptor inputs to glomeruli. $\boldsymbol{A}$, Pseudocolor maps of calcium signals evoked by methyl valerate before (left) and after (right) application of $1 \mathrm{~mm} \mathrm{CGP35348,} \mathrm{with} \mathrm{each} \mathrm{map} \mathrm{normalized}$ to its own maximum. Maps show the same data as in Figure $1 A$. The relative patterns are nearly identical. $\boldsymbol{B}$, Relative distributions of response amplitudes in different glomeruli before and after CGP35348. For each experiment, responses were normalized to the maximal glomerular response, with control and CGP35348 responses normalized separately. The relative distributions are identical (for statistical tests, see Results). C, CGP35348 did not preferentially enhance responses in glomeruli with strongly activated surrounds. Plots show ratio of the effect of CGP35348 on glomerular surrounds to its effect on the glomerulus, plotted as a function of the ratio of the predrug response of a glomerulus relative to it surround. Left plot, Vehicle control; right plot, CGP35348 experiments. Lines show the fit of the function $y=1+a \log (x / b)$ to the data. A horizontal fit indicates no relationship between center-surround ratio and CGP35348 effects (for statistical tests, see Results).

Third, we tested whether odorant-evoked presynaptic calcium influx in one glomerulus was suppressed when a neighboring glomerulus was coactivated. The experimental design was identical to that of our previous study imaging $\mathrm{SpH}$ signals (McGann et al., 2005): two odorants evoking input to neighboring glomeruli were presented either alone or as a binary mixture on interleaved trials. In the example of Figure $4 A$, butyl acetate (BA) and methyl valerate (MV) evoke input to primarily distinct sets of glomeruli, with MV-activated glomeruli surrounding a glomerulus activated strongly by BA. When the two odorants are pre- 
A

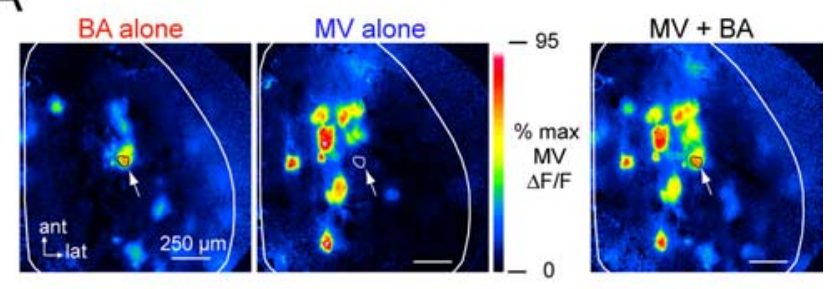

B

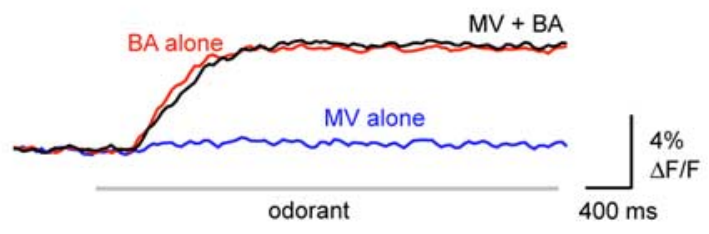

C
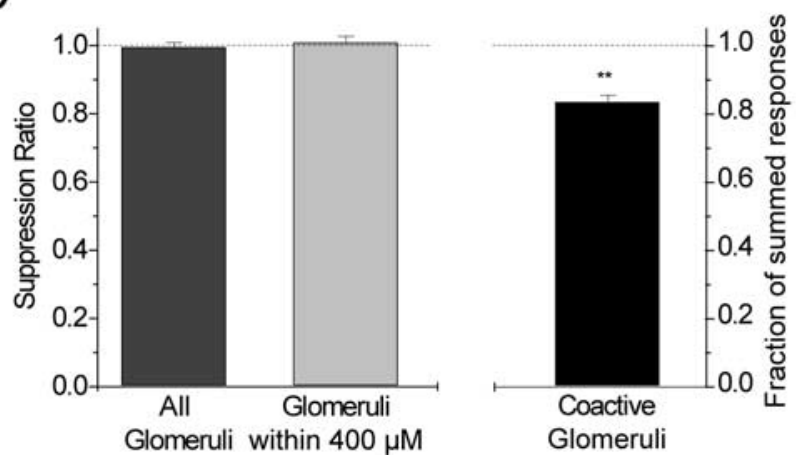

Figure 4. Receptor inputs are unaffected by odorant-evoked coactivation of neighboring glomeruli. $\boldsymbol{A}$, Pseudocolor maps of responses to BA alone (1\% s.v.; left), MV alone ( $0.5 \%$ s.V.; middle), or the binary mixture of $M V+B A$ (right). Maps are scaled relative to the odorant that evoked the highest response amplitude (methyl valerate). Arrow indicates BA-responsive glomerulus shown in $\boldsymbol{B}$. MV does not evoke signals in this glomerulus but does evoke strong signals in surrounding glomeruli. $\boldsymbol{B}$, Traces showing the calcium signal in this glomerulus in response to $B A$ alone (red), MV alone (blue), and the binary mixture of BA + MV (black). The response to the mixture is not different from the response to BA alone. C, Summary data showing SR calculated for all glomeruli activated by only one of the odorants in the pair (dark gray bar) and for a subset of these glomeruli that were within $400 \mu \mathrm{m}$ of a glomerulus activated by the other odorant (light gray bar). Neither of the two groups shows any significant suppression. Black bar shows responses of glomeruli activated by each odorant in the pair and shows responses to the mixture, with response amplitudes normalized to the sum of the response to each odorant alone. Responses are significantly smaller than predicted from the sum of the single-odorant responses ( $\left.{ }^{* *} p<0.0001\right)$. ant, Anterior; lat, lateral.

sented together, the response of this BA-activated glomerulus is identical in amplitude and temporal dynamics to when BA is presented alone (Fig. $4 B$ ), indicating that coactivation of neighboring glomeruli does not suppress presynaptic calcium influx into this glomerulus. To test for lateral inhibition between many glomeruli, we repeated this experiment for different odorant pairings (seven binary mixtures, three animals) and calculated a suppression ratio (SR) for all glomeruli activated by either odorant, defined as the ratio of the response evoked by the binary mixture to that evoked by the single odorant alone (Fig. 4C). For glomeruli responsive to only one odorant, there was no significant suppression $(\mathrm{SR}=0.99 \pm 0.013$; one-group $t$ test, $p=$ $0.7427 ; 142$ glomeruli, 3 animals). Restricting the analysis to include only glomeruli within $400 \mu \mathrm{m}$ of a glomerulus activated by the other odorant of the pair yielded a similar SR $(1.01 \pm 0.018$; one-group $t$ test, $p=0.6115 ; 89$ glomeruli, 3 animals). For glomeruli activated by both odorants, we calculated the ratio of the response to the mixture relative to the sum of the responses to each odorant alone and found significant sublinear addition of responses to the mixture $(0.84 \pm 0.02$; one-group $t$ test, $p<$ $0.0001 ; 68$ glomeruli, 3 animals). These results are identical to those obtained previously using $\mathrm{SpH}$ to monitor presynaptic regulation of transmitter release from ORNs (McGann et al., 2005). Together, this set of experiments indicates that inhibition between glomeruli does not affect ORN input to the OB at the level of presynaptic calcium influx.

\section{Both feedback and tonic presynaptic inhibition regulate ORN} inputs in vivo

In vivo, ORN inputs might be regulated by both tonic and stimulus-evoked feedback inhibition of presynaptic calcium influx (Aroniadou-Anderjaska et al., 2000; Wachowiak et al., 2005). The large effect of $\mathrm{GABA}_{\mathrm{B}}$ receptor blockade on responses to the first sniff of an odorant is consistent with tonic inhibition. However, feedback inhibition could also suppress responses to the first sniff of odorant if a single sniff evoked a prolonged burst of ORN firing. In OB slice preparations, ON shock elicits strong feedback inhibition at the ORN terminal within $50 \mathrm{~ms}$ and reaches maximal strength within $100 \mathrm{~ms}$ (Wachowiak et al., 2005). Sniff-evoked calcium signals in our artificial sniff paradigm had a rise time of $100-200 \mathrm{~ms}$ (Fig. 5A), similar to that measured for sniff-evoked presynaptic calcium signals in awake, freely respiring rats (Verhagen et al., 2007), indicating that a single sniff evokes a burst of ORN firing lasting for at least $100 \mathrm{~ms}$. Thus, feedback inhibition might regulate the strength of ORN inputs even during the course of a single sniff.

We used electrical stimulation of ORN axons to separate the contributions of tonic and feedback inhibition in vivo. A concentric bipolar electrode was placed on the OB surface at a point in the anterior $\mathrm{OB}$ containing a high density of caudally projecting ORN axons (Fig. 5B). A single (0.1 ms, 600-950 $\mu \mathrm{A})$ shock evoked calcium signals in glomeruli across the dorsal OB, many of which were located a considerable distance $(>500 \mu \mathrm{m})$ from the stimulating electrode (Fig. 5B). ON-evoked glomerular response patterns were highly reproducible across trials (Pearson's $r=0.93 \pm 0.014$; 91 comparisons, 9 animals) and were typically oriented caudal to the stimulating electrode (Fig. $5 B$ ), consistent with propagation of shock-evoked action potentials into ORN terminals rather than direct excitation of terminals by current spread from the electrode. The fast rise time of the shock-evoked response ( $\sim 24 \mathrm{~ms}$ for the example glomeruli in Fig. $5 B)$ eliminated the possibility that feedback inhibition could affect the amplitude of the response to a single shock; any effect of $\mathrm{GABA}_{\mathrm{B}}$ receptor blockade on this response would thus reflect tonic inhibition at the ORN terminal. Indeed, CGP35348 caused responses to a single $\mathrm{ON}$ shock to increase to $138 \pm 4.1 \%$ of predrug amplitudes (one group $t$ test, $p<0.0001 ; 53$ glomeruli, 9 animals) without changing the rise time or decay of the response (Fig. $5 C$ ). Thus, tonic inhibition strongly regulates spike-evoked calcium influx into the ORN axon terminal in vivo.

Next, we used paired ON shocks to test for feedback inhibition at the presynaptic terminal. Consistent with analogous experiments in vitro (Wachowiak et al., 2005), we observed significant paired-pulse suppression of the calcium signal (Fig. 6A). Pairedpulse suppression was maximal at the shortest interstimulus interval (ISI) tested (200 ms; we did not measure paired-pulse ratios (PPRs) for ISIs $<200 \mathrm{~ms}$ because of potential errors from dye saturation) and decayed gradually over the next 600-800 ms (predrug decay time constant, $306 \pm 99.7$ ms; CGP35348 decay time constant, $268 \pm 118.7 \mathrm{~ms}$ ) (Fig. 6B). CGP35348 significantly increased the paired-pulse ratio (300 ms ISI predrug, 
$0.66 \pm 0.02 ; \mathrm{CGP} 35348,0.75 \pm 0.011$; paired $t$ test, $p<0.0001 ; 39$ glomeruli, 7 animals). This effect was modest, however, and paired-pulse suppression remained at all ISIs in the presence of $\mathrm{GABA}_{\mathrm{B}}$ receptor blockade (Fig. 6B, C). CGP35348 strongly increased conditioning response in these same trials (see above) (Fig. 6C), indicating that the persistent paired-pulse suppression was not attributable to ineffective drug application. Instead, additional feedback inhibition may be mediated by other transmitter pathways (Hsia et al., 1999; Ennis et al., 2001; Murphy and Isaacson, 2003). Persistent paired-pulse suppression at the shortest ISIs may also reflect mechanisms intrinsic to the presynaptic terminal, such as calcium channel inactivation.

Finally, we asked whether both tonic and shock-evoked feedback inhibition are present under a different anesthetic regimen by repeating the ON shock experiments in mice anesthetized with isoflurane. As with pentobarbital anesthesia, $\mathrm{GABA}_{\mathrm{B}}$ receptor blockade caused a large increase in the conditioning pulse response (138 $\pm 6.3 \%$; one-group $t$ test, $p<$ 0.0001 ; 20 glomeruli, 3 animals), indicating strong tonic inhibition; conversely, there was no effect of CGP35348 on the paired-pulse ratio (300 ms ISI predrug, $0.74 \pm 0.022$; CGP35348, $0.74 \pm 0.022$; paired $t$ test, $p=0.9867 ; 20$ glomeruli, 3 animals). Thus, $\mathrm{GABA}_{\mathrm{B}}$-mediated tonic inhibition of ORN inputs is strong under at least two anesthetic regimens, whereas $\mathrm{GABA}_{\mathrm{B}}$-mediated feedback inhibition is relatively weak.

\section{Feedback inhibition evoked by a single sniff}

We next asked to what degree feedback inhibition evoked by a single sniff modulates ORN inputs. Whereas ON shocks can elicit strong feedback inhibition in vivo and in OB slices (Aroniadou-Anderjaska et al., 2000; Wachowiak et al., 2005), ORN inputs evoked during sniffing are asynchronous and occur over a time window of $100 \mathrm{~ms}$ or more (Fig. $5 \mathrm{~A}$ ) (Verhagen et al., 2007). To assess the degree to which sniffevoked ORN inputs elicit feedback inhibition within a glomerulus, we used a sniff as the conditioning stimulus and a single $\mathrm{ON}$ shock as the test stimulus and asked whether sniff-evoked activation of a glomerulus suppressed the response of that glomerulus to the test shock. An example experiment is shown in Figure 7A, in which an odorant (methyl valerate) evokes input to a set of dorsal glomeruli and $\mathrm{ON}$ shock evokes input to a different but overlapping set of glomeruli. Odorant-evoked signals were measured in response to a single artificial sniff of odorant. The test shock was delivered at one of two times after the peak of the odorant-evoked response: either at a delay of $\sim 400 \mathrm{~ms}$ (corresponding to a time when feedback inhibition should be strong) or at a delay of $>1 \mathrm{~s}$ (corresponding to time when feedback inhibition should be primarily recovered). Shock-evoked response amant, Anterior; lat, lateral.
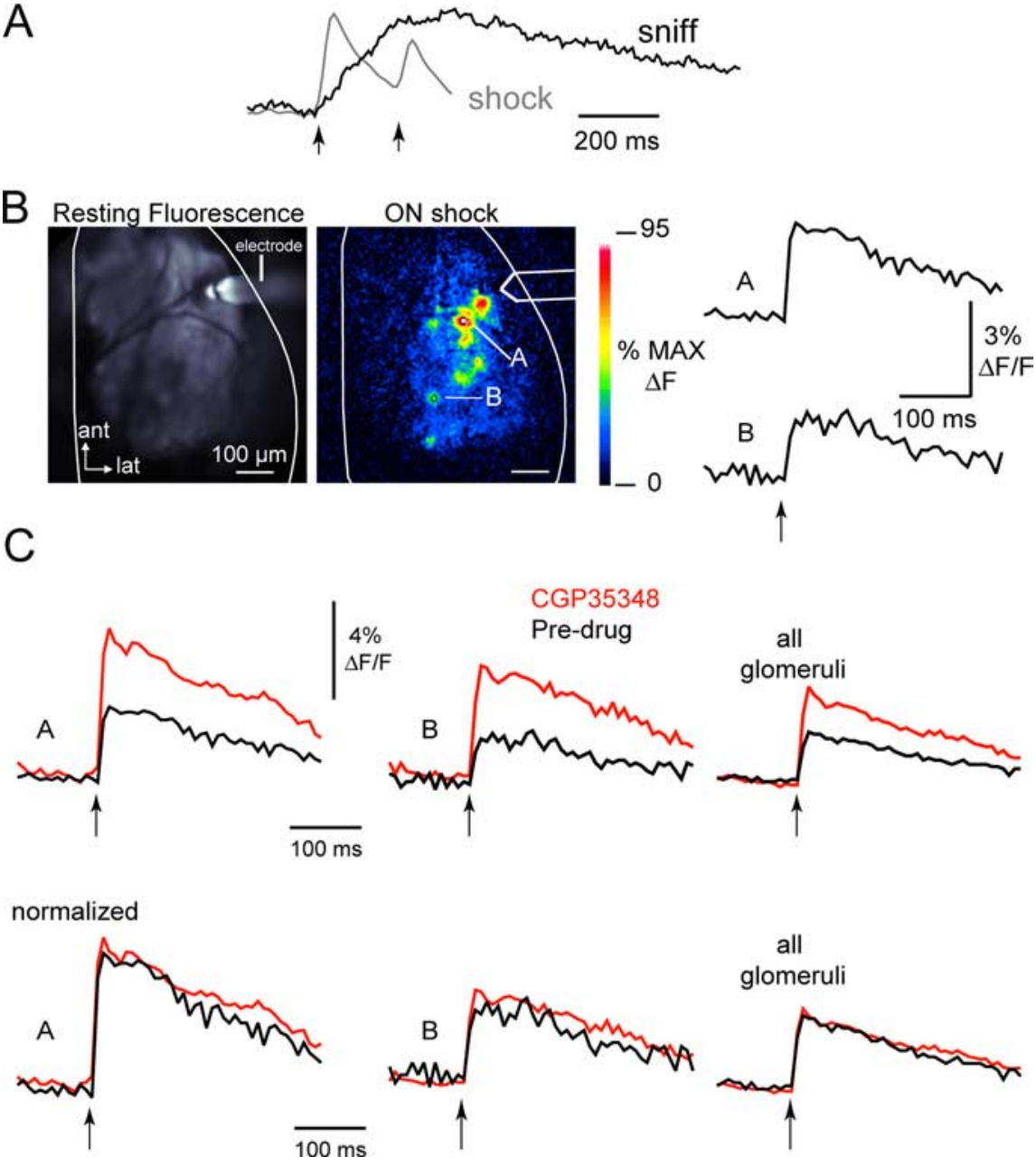

Figure 5. Tonic presynaptic inhibition regulates receptor input to the olfactory bulb in vivo. $\boldsymbol{A}$, Traces of presynaptic calcium signals evoked by a single artificial sniff of odorant (black) and by paired ON shocks ( $200 \mathrm{~ms}$ ISI) in a slice preparation (gray). The

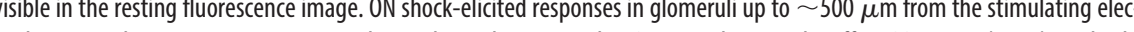
evoked responses. Top traces show signals in glomerulus $A$, glomerulus $B$, and an average of all responsive glomeruli in this preparation, and bottom traces show responses in the same glomeruli but scaled to the same amplitude. Signals are unfiltered.

plitudes were then compared with those delivered without a preceding odorant response.

Glomeruli that were activated by $\mathrm{ON}$ shock but not by the odorant (glomerulus 2 in Fig. 7A) showed no effect of odorant presentation (Fig. $7 B$ ). At the $400 \mathrm{~ms}$ post-sniff interval, responses were $0.97 \pm 0.02$ of those elicited by ON shock alone (one-group $t$ test, $p=0.06 ; 45$ glomeruli, 8 animals). This result is consistent with the conclusion that interglomerular inhibition does not shape ORN inputs presynaptically. In contrast, $\mathrm{ON}$ shock responses in glomeruli receiving sniff-evoked input (glomerulus 1 in Fig. 7A) did show suppression, with responses to the $400 \mathrm{~ms}$ post-sniff $\mathrm{ON}$ shock suppressed to $0.77 \pm 0.017$ of shockalone trials (one group $t$ test, $p<0.0001 ; 67$ glomeruli, 8 animals). This suppression was nearly, although not entirely, eliminated at the longer post-sniff interval (1.0-1.8 s; mean, $1.2 \pm$ $0.04 \mathrm{~s}$ ), with post-sniff responses reduced to $0.91 \pm 0.022$ of shock-alone amplitudes (one group $t$ test, $p=0.0005 ; 43$ glomeruli, 5 animals). Some suppression of post-sniff responses at the 


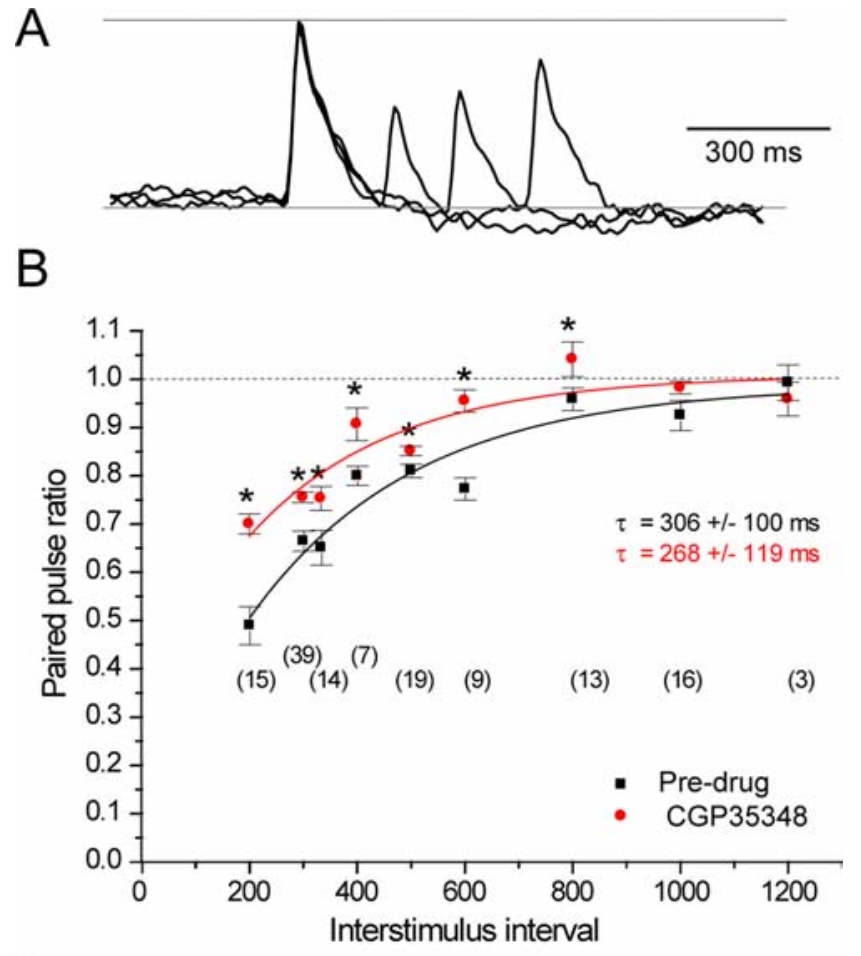

C
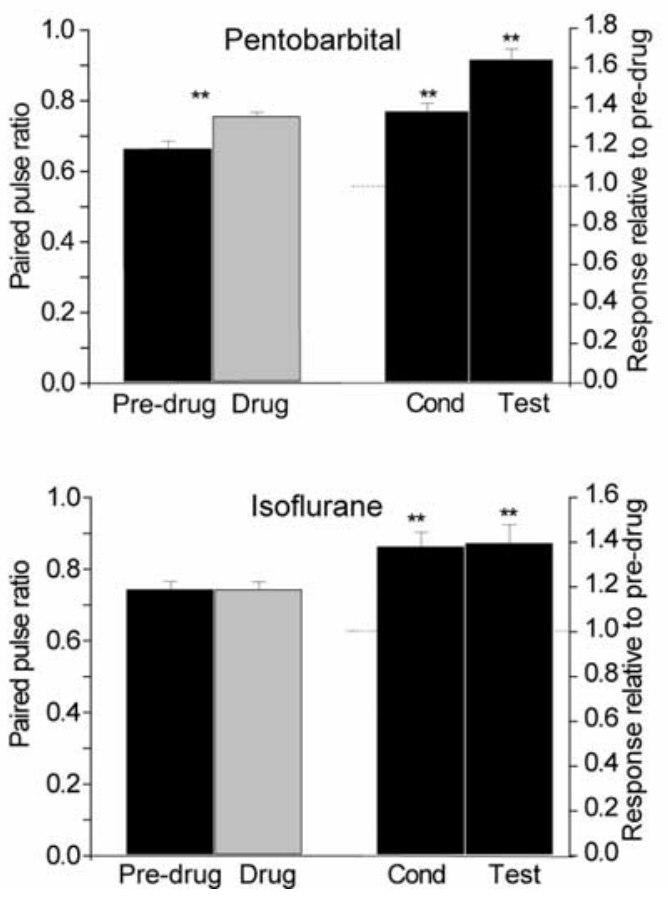

Figure 6. $G A B A_{B}$-mediated feedback inhibition of receptor inputs in vivo. $\boldsymbol{A}$, Responses of one glomerulus to paired in vivo $0 \mathrm{~N}$ shocks delivered at ISIs from 200 to $500 \mathrm{~ms}$. Traces are scaled to the same peak amplitude and bandpass filtered (low-pass Gaussian, cutoff at $18 \mathrm{~Hz}$, highpass digital $\tau$ filter, $1.4 \mathrm{~Hz}$ cutoff) to facilitate comparison. $B$, PPR (test: conditioning response amplitude) as a function of ISI before (black squares) and after (1 mm, red circles) CGP35348. PPR recovers with a time constant of $\sim 300 \mathrm{~ms}$. CGP35348 increases the PPR at all ISIs, but significant paired-pulse suppression remains at ISIs below $600 \mathrm{~ms} .{ }^{*} p<0.05$ relative to predrug PPR. C, Summary of effects of CGP35348 on 0N shock-evoked responses. Left, PPR before and after CGP35348 (300 ms ISI). Right, Responses to the conditioning and test ON shocks in (GP35348 relative to predrug levels $\left({ }^{* *} p<0.0001\right)$. Both conditioning and test responses increase, consistent with $\mathrm{GABA}_{B}$-mediated tonic and feedback inhibition. $\boldsymbol{D}$, Effects of CGP35348 on ON shock-evoked responses under isoflurane anesthesia. Whereas conditioning and test responses increase, PPR is unchanged, suggesting an absence of $G A B A_{B}$-mediated feedback inhibition under isoflurane.
$400 \mathrm{~ms}$ interval may be attributed to a prolonged sniff-evoked activation of ORNs causing reduced shock-evoked responses reflecting refractoriness or calcium channel inactivation. This effect is unlikely to contribute to the suppression remaining at the $1 \mathrm{~s}$ post-sniff interval because, by this time, the sniff-evoked calcium signals have returned completely to baseline. Overall, these data suggest that ORN inputs evoked by naturalistic odorant inhalation elicit at least some intraglomerular feedback inhibition of subsequent inputs.

\section{What drives tonic inhibition in vivo?}

Tonic inhibition of ORN inputs in vivo could be driven by at least three possible pathways. First, GABAergic periglomerular interneurons could show high spontaneous activity and consequent GABA release in the absence of excitatory drive (Puopolo et al., 2005). Second, GABAergic interneurons could be tonically excited by spontaneously active ORN inputs. Third, GABAergic interneurons could be tonically driven by other excitatory inputs, for example, from glutamatergic short-axon cells (Aungst et al., 2003) or external tufted (ET) cells (Hayar et al., 2004b). We attempted to distinguish between these three possibilities with the following experiments.

If tonic presynaptic inhibition results from intrinsically active GABAergic interneurons, this inhibition should persist after blockade of excitatory glutamatergic transmission. To test this, we applied NBQX $(200 \mu \mathrm{M})$ to the dorsal OB to block AMPAtype glutamate receptors. In OB slices, AMPA receptor blockade eliminates spontaneous and evoked EPSCs in periglomerular interneurons (Hayar et al., 2004b). We did not attempt to block NMDA receptors with APV; APV alone has little effect on presynaptic inhibition in $\mathrm{OB}$ slice preparations (McGann et al., 2005). NBQX caused an increase in the response to the conditioning ON shock (Fig. $8 A$ ), to $123 \pm 2.44 \%$ of predrug levels (one-group $t$ test, $p<0.0001 ; 38$ glomeruli, 4 animals). This result indicates that a significant component of tonic inhibition is driven by glutamatergic excitation of periglomerular interneurons. To test for residual $\mathrm{GABA}_{\mathrm{B}}$-mediated inhibition in the absence of AMPA receptor signaling, we applied CGP35348 after NBQX application. CGP35348 caused an additional increase in conditioning response amplitude, to $117 \pm 2.65 \%$ of NBQXalone levels (one group $t$ test, $p<0.0001 ; 38$ glomeruli, 4 animals), suggesting some residual contribution from spontaneously active periglomerular interneurons in setting tonic inhibition.

Next we asked whether the source of tonic excitatory input to inhibitory juxtaglomerular interneurons arises from spontaneously active ORNs. We tested this hypothesis by performing paired ON shock experiments before and after applying TTX to the olfactory epithelium in vivo. An example of this experiment is shown in Figure 8 B. First, paired ON shocks were delivered to the dorsal $\mathrm{OB}$, followed $\sim 2.5 \mathrm{~s}$ later by odorant presentation, allowing us to image both shock- and odorant-evoked signals in overlapping sets of glomeruli. TTX $(4 \mu \mathrm{l}, 10 \mu \mathrm{M})$ was then applied to the olfactory epithelium by using artificial inhalation to draw the solution into the nasal cavity on the imaged side. TTX application invariably eliminated or strongly reduced odorant-evoked responses immediately after application (Fig. $8 B, C$ ). In some preparations, successful application was further confirmed by including a small amount of fluorescent dye (Alexa Fluor 568, 0.002\%; Invitrogen) in the TTX solution and examining its distribution in the nasal cavity after the end of the experiment (data not shown).

Peripheral TTX application nearly eliminated evoked and presumably also spontaneous ORN firing but had no effect on the 
A

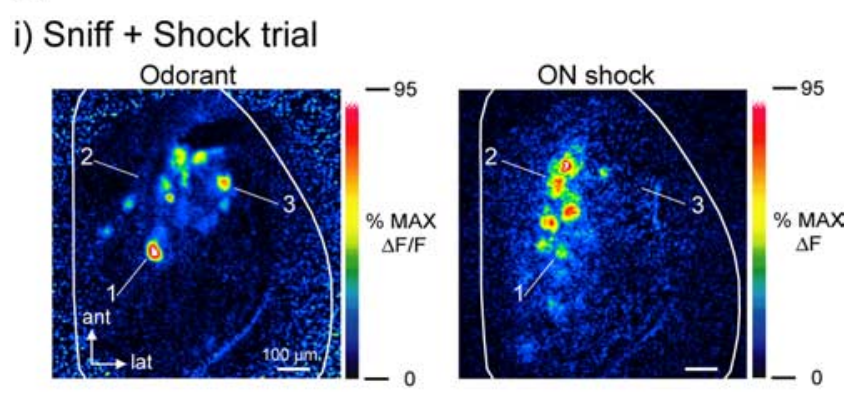

ii) Sniff + Shock

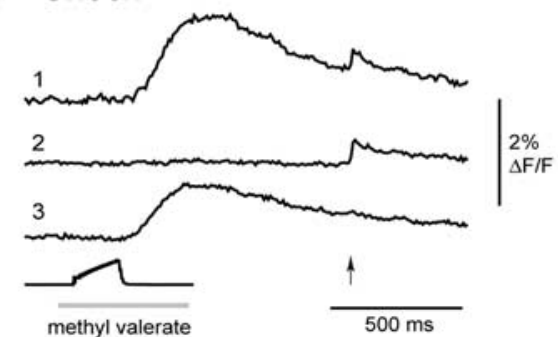

iii) Sniff + Late shock

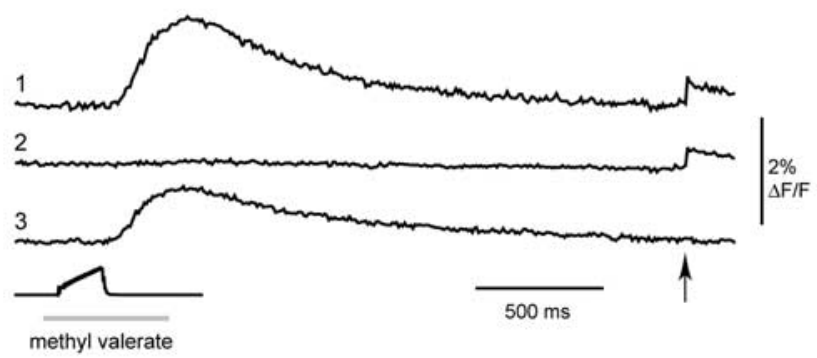

iv)

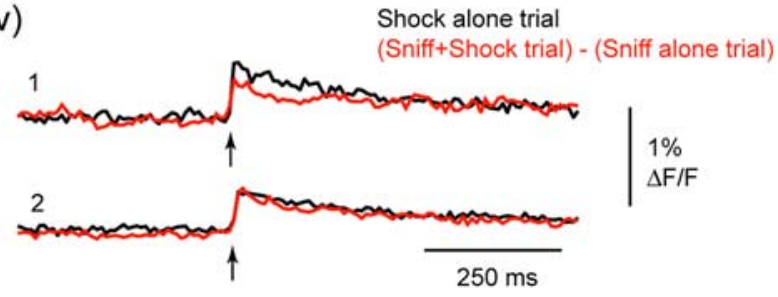

B

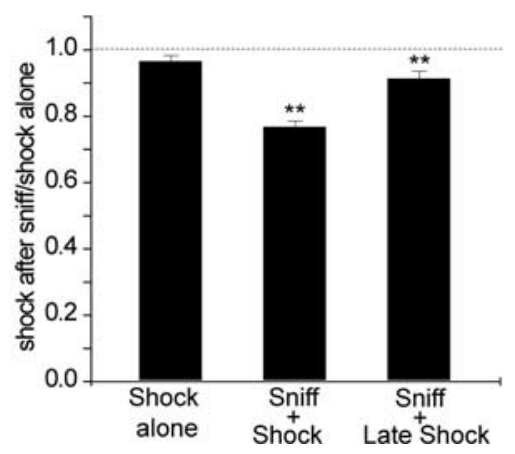

Figure 7. Feedback inhibition of receptor inputs evoked by a single sniff of odorant. $\boldsymbol{A}$, Example of sniff-shock experiment. $\boldsymbol{i}$, Pseudocolor maps of the response to a single artificial sniff of odorant (left) and a single ON shock (right) in the same preparation. Glomerulus 1 is activated by both the sniff and shock. Glomerulus 2 is activated only by shock, and glomerulus 3 is only activated by the odorant. ii, Traces showing the response of glomeruli $1-3$ to a sniff of odorant (methyl valerate, $1 \%$ s.v.) followed $\sim 400$ ms later by an 0 N shock (delivered at arrow). iii, Traces of a trial in which the shock was delivered late $(\sim 1.8 \mathrm{~s})$ after the sniff-driven odorant response. ON shocks were also delivered without odorant stimulation (data not shown). iv, Comparison of shock-evoked responses in which the shock was delivered alone (black) relative to trials in which the shock was preceded by a sniff of odorant $\sim 400 \mathrm{~ms}$ earlier (red). Traces are magnitude of presynaptic calcium signals evoked by ON shock (Fig. $8 B$ ). The response to a single ON shock was $94 \pm 4.6 \%$ of predrug amplitudes (one group $t$ test, $p=0.2119 ; 30$ glomeruli, 4 animals), whereas the response to odorant stimulation was $-2 \pm$ $1.3 \%$ of predrug amplitudes (one-group $t$ test, $p<0.0001 ; 39$ glomeruli, 4 animals). Paired-pulse ratio (300 ms ISI) was also unchanged (predrug, $0.69 \pm 0.022$; TTX, $0.68 \pm 0.024$; paired $t$ test, $p=0.7505 ; 23$ glomeruli, 3 animals) (Fig. $8 C$ ). To ensure that changes in tonic and feedback inhibition were still detectable after TTX application, in some preparations, we next applied CGP35348 to block $\mathrm{GABA}_{\mathrm{B}}$-mediated inhibition. As expected, CGP35348 caused an increase in conditioning response amplitude $(142 \pm 11.1 \%$ of predrug values; one-group $t$ test, $p=$ 0.0006; 30 glomeruli, 4 animals), as well as an increase in pairedpulse ratio (TTX, $0.68 \pm 0.026$; TTX + CGP35348, $0.84 \pm$ 0.0315 ; paired $t$ test, $p<0.0001 ; 23$ glomeruli, 3 animals) (Fig. $8 C$ ). This result suggests that spontaneous ORN firing does not play a major role in setting the strength of tonic or feedback presynaptic inhibition, at least in anesthetized mice. Together, these experiments suggest that tonic presynaptic inhibition is primarily driven by excitatory, glutamatergic inputs to periglomerular interneurons. Potential circuit mechanisms underlying this tonic drive are discussed below.

\section{Discussion}

Sensory input to the olfactory bulb is regulated by synaptic inhibition directed at the presynaptic terminal of ORNs. Here, we have tested predictions of the functional organization of this inhibition in vivo, focusing on the relationship between $\mathrm{GABA}_{\mathrm{B}}$ receptor-mediated presynaptic inhibition and the magnitude, spatial organization, and temporal dynamics of odorant-evoked inputs to olfactory bulb glomeruli. We found that the strength of $\mathrm{GABA}_{\mathrm{B}}$-mediated presynaptic inhibition is similar for both weak and strong odorant-evoked inputs, independent of the spatial organization of activated glomeruli and also independent of the frequency of sniff-driven inputs. We also found that ORN inputs are strongly regulated by tonic presynaptic inhibition and that this tonic inhibition is dependent on glutamatergic transmission in the glomerular layer.

\section{Functional determinants of $\mathrm{GABA}_{B}$-mediated presynaptic inhibition}

One hypothesized role of presynaptic inhibition is as an adaptive gain control mechanism in which weak inputs are subject to less inhibition than strong inputs, increasing the dynamic range of sensory input to a glomerulus (Nickell et al., 1994; McGann et al., 2005; Olsen and Wilson, 2008). However, we found that, when ORN inputs are activated by odorant inhalation, weak odorantevoked inputs are subject to a similar degree of $\mathrm{GABA}_{\mathrm{B}}$-mediated presynaptic inhibition as are strong inputs. This result suggests that, at least in mammals, presynaptic inhibition serves mainly to set the sensitivity of ORN inputs rather than their dynamic range. This prediction could be tested by measuring glomerular input-

$\leftarrow$

for glomeruli 1 and 2 from $A$. Glomerulus 1 shows suppressed responses after a sniff of odorant, whereas glomerulus 2 (which does not respond to the odorant) does not. $\boldsymbol{B}$, Summary data showing the shock-evoked response after a sniff of odorant relative to the response without a preceding sniff. Data are shown for glomeruli responding to shock but not odorant (left bar) and those responding to both shock and odorant (middle, right bars). Only odorant-responsive glomeruli showed suppression after a sniff, with stronger suppression at $\sim 400 \mathrm{~ms}$ after the sniff-driven response and weak suppression at $\sim 1-1.8 \mathrm{~s}$ after the response. ${ }^{* *} p<0.01$ relative to shock-alone response. ant, Anterior; lat, lateral. 

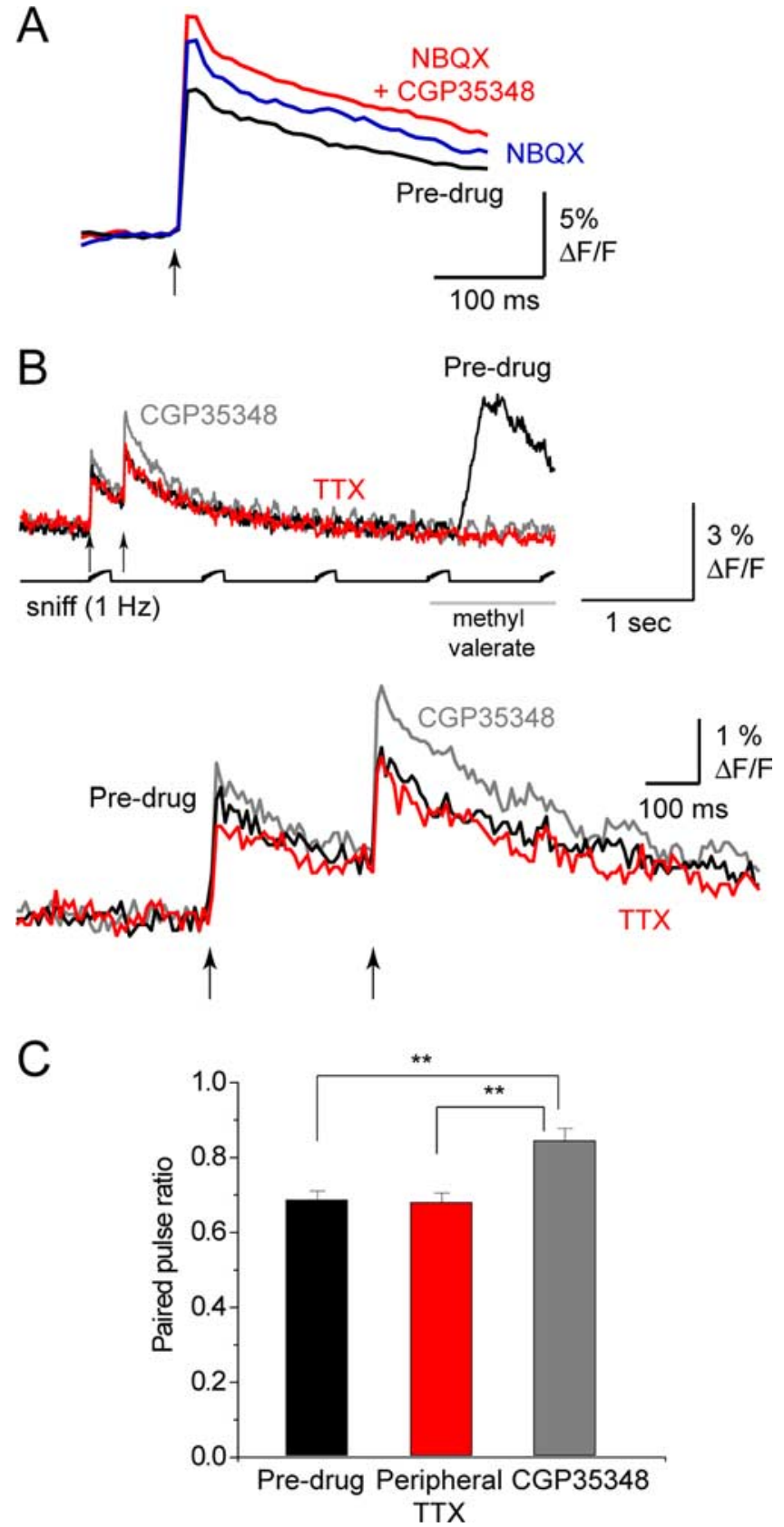

Figure 8. Tonic presynaptic inhibition depends on glutamatergic transmission but not on spontaneous activity in receptorneurons. $A$, Traces showing the response of a glomerulus to a single $0 \mathrm{~N}$ shock $(650 \mu \mathrm{A})$ in control Ringer's solution (black), after application of NBQX (200 $\mu \mathrm{m}$, middle blue trace), and then after application of NBQX + CGP35348 (1 mm) (top, red trace). The largest increase occurs after NBQX application, with an additional increase after addition of CGP35348. B, Traces showing the response of a glomerulus to paired $0 \mathrm{~N}$ shock, followed $\sim 2.5$ slater by presentation of methyl valerate (0.5\% s.v., gray bar, artificial sniffing at $1 \mathrm{~Hz}$ ). Black trace shows predrug responses. Applying $\Pi \mathrm{TX}(10$ $\mu \mathrm{M}$, red trace) to the olfactory epithelium eliminates the odorant-evoked response with no significant change in the ON shock response. Applying (GP35348 (1 mm, gray trace) next increases ON shockevoked responses, whereas odorant-evoked responses remain blocked. Bottom trace shows expansion of $\mathrm{ON}$ shock responses to facilitate comparison. Conditioning response amplitude shows slight rundown after TX application and a large increase after CGP35348 application. The test response is unchanged by TTX but strongly increased by CGP35348. C, Effect of drug treatments on PPR of ON shock-evoked responses (300 ms ISI). TXX had no effect on PPR, whereas (GP35348 significantly increased PPR ( ${ }^{* *} p<0.0001$ relative to predrug PPR).

output relationships in the presence and absence of $\mathrm{GABA}_{\mathrm{B}}$ receptor antagonists.

Another hypothesized role of presynaptic inhibition has been to sharpen odorant representations via interglomerular inhibi- tory interactions (Nickell et al., 1994; Wachowiak and Cohen, 1999; Vucinic et al., 2005). Short-axon cells in the glomerular layer mediate interglomerular inhibition of postsynaptic activity (Aungst et al., 2003), and, in OB slices, modest interglomerular presynaptic inhibition can be evoked by strong ON stimulation protocols (McGann et al., 2005). Interglomerular presynaptic inhibition has been reported recently to shape odor coding in the Drosophila antennal lobe (Olsen and Wilson, 2008). Conflicting data exist, however, on whether interglomerular inhibition shapes odorant-evoked ORN inputs to the mammalian $\mathrm{OB}$ in vivo (McGann et al., 2005; Vucinic et al., 2005).

Four lines of evidence support the conclusion that interglomerular presynaptic inhibition does not regulate the strength of ORN input to the OB. First, using the same imaging and analysis methods as in the study by Vucinic et al. (2005), we found no relationship between the effect of $\mathrm{GABA}_{\mathrm{B}}$ receptor blockade and the spatial organization of odorant-evoked inputs. Weak inputs located in regions surrounding strongly activated glomeruli showed the same effect of $\mathrm{GABA}_{\mathrm{B}}$ blockade as strong inputs in the surrounds of weakly activated glomeruli. Second, spatial maps of ORN input showed no significant change in their relative patterns of activation after $\mathrm{GABA}_{\mathrm{B}}$ blockade, despite a significant increase in their absolute response amplitudes. Third, odorantevoked input to one glomerulus did not alter the magnitude of calcium influx in neighboring glomeruli activated by a different odorant. Fourth, in experiments using odorant inhalation as a conditioning stimulus and a single ON shock as the test stimulus, odorant inhalation suppressed shock-evoked inputs only to those glomeruli activated by the odorant but did not affect inputs to neighboring glomeruli not activated by the odorant. Together, these results suggest that interglomerular inhibition does not modulate ORN inputs in vivo, consistent with our previous study based on direct imaging of transmitter release from ORNs (McGann et al., 2005). This organization appears different from that seen in the Drosophila antennal lobe (Olsen and Wilson, 2008), in which a widespread interglomerular circuit appears to regulate ORN input. In the mammalian $\mathrm{OB}$, widespread interglomerular inhibition having similar functional consequences may be mediated postsynaptically via a circuit involving short-axon cells, external tufted cells, and periglomerular interneurons (Aungst et al., 2003; Cleland and Sethupathy, 2006; Wachowiak and Shipley, 2006).

Presynaptic inhibition has also been hypothesized to preferentially suppress ORN inputs during high-frequency $(4-10 \mathrm{~Hz})$ sniffing, which could facilitate the detection of novel odorants against a background (Aroniadou-Anderjaska et al., 2000; Wachowiak and Shipley, 2006). However, we found no effect of sniff frequency on the strength of $\mathrm{GABA}_{\mathrm{B}}$-mediated presynaptic inhibition; instead, this inhibition suppressed presynaptic calcium influx as strongly for ORN inputs evoked by the first inhalation of odorant as for subsequent inhalations, regardless of frequency. There are two likely explanations for this observation. First, the rise time of the sniff-evoked presynaptic calcium signal is $\sim 100 \mathrm{~ms}$, suggesting that sniff-driven ORN inputs are spread across a time window sufficient for intraglomerular feedback inhibition onto the ORN terminal to reach maximal strength in the course of a single sniff-driven burst of input. Second, if tonic inhibition is a major determinant of the strength of ORN inputs, changes in sniff frequency may have little additional effect.

Tonic presynaptic inhibition at the receptor neuron terminal Our data suggest that tonic inhibition onto ORN terminals strongly regulates the strength of sensory input to the $\mathrm{OB}$ in vivo. 
Tonic $\mathrm{GABA}_{\mathrm{B}}$-mediated inhibition was apparent under different anesthesia regimens (pentobarbital and isoflurane); we predict that such inhibition also occurs in awake mice, although this remains to be tested. This result differs from that seen in mouse $\mathrm{OB}$ slice preparations: in the slice, $\mathrm{GABA}_{\mathrm{B}}$ receptor blockade has no effect on conditioning pulse responses measured with the same stimulus protocol and imaging method, suggesting that tonic inhibition is much weaker or absent under these conditions (Wachowiak and Cohen, 1999; Wachowiak et al., 2005). Tonic inhibition is also not apparent when transmitter release from ORN terminals is monitored directly in slices (McGann et al., 2005). Thus, several functional properties of presynaptic inhibition of ORN inputs appear qualitatively different in slice versus in vivo preparations; it will be interesting to examine other features of signaling in the OB network that have been primarily or exclusively characterized in slice preparations.

There are several caveats to these interpretations. First, it is possible that a substantial level of odorant-evoked ORN input is undetected with our imaging method. If this were true, even response amplitudes of $10-20 \%$ of the maximal response may represent strong inputs to a glomerulus; if so, it remains possible that "truly" weak inputs may in fact be differentially regulated by presynaptic inhibition. One argument against this possibility is the fact that CGP35348 failed to reveal activated glomeruli that were not apparent before drug application (Fig. $1 \mathrm{~A}$ ), as would be expected if there were significant numbers of glomeruli receiving weak but undetectable input. A second caveat is that our imaging method reports the average level of activity across all inputs to a glomerulus, and different degrees of tonic versus feedback inhibition may occur for different inputs to the same glomerulus. Indeed, in mouse OB slices, different populations of periglomerular interneurons (i.e., those preferentially receiving monosynaptic vs disynaptic ORN input) are subject to differing degrees of feedback presynaptic inhibition (M. Shipley, personal communication). This heterogeneity of processing within the glomerulus may also explain why tonic $\mathrm{GABA}_{B}$-mediated presynaptic inhibition has been detected in $\mathrm{OB}$ slices using electrophysiological recordings (Aroniadou-Anderjaska et al., 2000) but not using glomerular imaging from all ORN terminals (McGann et al., 2005; Wachowiak et al., 2005).

It is nonetheless clear that tonic presynaptic inhibition plays a major role in regulating the strength of sensory input to the $\mathrm{OB}$ in vivo. What is the source of this inhibition? Our data suggest that tonic inhibition is primarily driven by excitatory, glutamatergic transmission in the glomerular layer. Our data rule out spontaneous activity in ORNs as a major source of this excitation, because peripheral application of TTX, which eliminated odorantevoked action potentials in ORNs, had no effect on shock-evoked responses. Instead, we hypothesize that glutamatergic interneurons in the glomerular layer excite GABAergic periglomerular interneurons, which in turn mediate presynaptic inhibition at the ORN terminal. Candidate interneurons include the ET cells, which spread excitation throughout a single glomerulus (Hayar et al., 2004b), and short-axon cells, which innervate many glomeruli (Aungst et al., 2003).

ET cells in particular have functional properties making them well suited to drive tonic inhibition within a glomerulus. First, ET cells are tonically active, firing bursts of spikes at regular intervals (Hayar et al., 2004a). Second, ET cells excite GABAergic periglomerular interneurons, with a single ET cell capable of activating multiple interneurons in the same glomerulus (Hayar et al., 2004b; Murphy et al., 2005). Third, the frequency and synchrony of ET cell bursting is modulated by sensory input (Hayar et al., 2004a) and likely by centrifugal inputs to the glomerulus (Aungst and Shipley, 2005). Thus, changes in ET cell firing could alter the degree of tonic presynaptic inhibition in a glomerulus-specific manner.

We hypothesize that, in the awake animal, tonic inhibition is modulated by centrifugal inputs to $\mathrm{OB}$ glomeruli, providing a means by which olfactory sensitivity can be altered depending on behavioral state. The major centrifugal inputs to OB glomeruli are cholinergic and serotonergic fibers from the basal forebrain and the raphe (McLean and Shipley, 1987; Gomez et al., 2005). Cholinergic agents applied to the $\mathrm{OB}$ alter odor detection thresholds (Mandairon et al., 2006), and serotonin excites juxtaglomerular interneurons, including ET cells, in OB slices (Aungst and Shipley, 2005; Hardy et al., 2005). Such modulation may occur slowly, e.g., during the sleep/wake cycle, or rapidly, e.g., during exploratory behavior. Layered on top of this tonic control of sensory input is an intraglomerular feedback component that serves to modulate inputs to individual glomeruli in an activitydependent manner. Thus, a rich repertoire of sensory processing phenomena may be mediated at levels as early as the first synapse in the olfactory system.

\section{References}

Aroniadou-Anderjaska V, Ennis M, Shipley MT (1999) Dendrodendritic recurrent excitation in mitral cells of the rat olfactory bulb. J Neurophysiol 82:489-494.

Aroniadou-Anderjaska V, Zhou F-M, Priest CA, Ennis M, Shipley MT (2000) Tonic and synaptically evoked presynaptic inhibition of sensory input to rat olfactory bulb via $\mathrm{GABA}_{\mathrm{B}}$ heteroreceptors. J Neurophysiol 84:1194-1203.

Aungst JL, Shipley MT (2005) Serotonin modulation of external tufted cells in mouse olfactory bulb glomeruli. Presented at the 27th Meeting of the Association of Chemoreception Sciences, Sarasota, FL, April.

Aungst JL, Heyward PM, Puche AC, Karnup SV, Hayar A, Szabo G, Shipley MT (2003) Centre-surround inhibition among olfactory bulb glomeruli. Nature 426:623-629.

Bonino M, Cantino D, Sassoe-Pognetto M (1999) Cellular and subcellular localization of gamma-aminobutyric acid ${ }_{\mathrm{B}}$ receptors in the rat olfactory bulb. Neurosci Lett 274:195-198.

Bozza T, McGann JP, Mombaerts P, Wachowiak M (2004) In vivo imaging of neuronal activity by targeted expression of a genetically encoded probe in the mouse. Neuron 42:9-21.

Cleland TA, Sethupathy P (2006) Non-topographical contrast enhancement in the olfactory bulb. BMC Neurosci 7:7.

Ennis M, Zhou F-M, Ciombor KJ, Aroniadou-Anderjaska V, Hayar A, Borrelli E, Zimmer LA, Margolis F, Shipley MT (2001) Dopamine D2 receptor-mediated presynaptic inhibition of olfactory nerve terminals. J Neurophysiol 86:2986-2997.

Gomez C, Brinon JG, Barbado MV, Weruaga E, Valero J, Alonso JR (2005) Heterogeneous targeting of centrifugal inputs to the glomerular layer of the main olfactory bulb. J Chem Neuroanat 29:238-254.

Hardy A, Palouzier-Paulignan B, Duchamp A, Royet JP, Duchamp-Viret P (2005) 5-hydroxytryptamine action in the rat olfactory bulb: In vitro electrophysiological patch-clamp recordings of juxtaglomerular and mitral cells. Neuroscience 131:717-731.

Hayar A, Karnup S, Shipley MT, Ennis M (2004a) Olfactory bulb glomeruli: external tufted cells intrinsically burst at theta frequency and are entrained by patterned olfactory input. J Neurosci 24:1190-1199.

Hayar A, Karnup S, Ennis M, Shipley MT (2004b) External tufted cells: a major excitatory element that coordinates glomerular activity. J Neurosci 24:6676-6685.

Hsia AY, Vincent J-D, Lledo P-M (1999) Dopamine depresses synaptic inputs into the olfactory bulb. J Neurophysiol 82:1082-1085.

Kratskin I, Kenigfest N, Rio JP, Djediat C, Reperant J (2006) Immunocytochemical localization of the GABAB2 receptor subunit in the glomeruli of the mouse main olfactory bulb. Neurosci Lett 402:121-125.

Mandairon N, Ferretti CJ, Stack CM, Rubin DB, Cleland TA, Linster C (2006) Cholinergic modulation in the olfactory bulb influences spontaneous olfactory discrimination in adult rats. Eur J Neurosci 24:3234-3244. 
McGann JP, Pírez N, Gainey MA, Muratore C, Elias AS, Wachowiak M (2005) Odorant representations are modulated by intra- but not interglomerular presynaptic inhibition of olfactory sensory neurons. Neuron 48:1039-1053.

McLean JH, Shipley MT (1987) Serotonergic afferents to the rat olfactory bulb. I. Origins and laminar specificity of serotonergic inputs in the adult rat. J Neurosci 7:3016-3028.

Murphy GJ, Isaacson JS (2003) Presynaptic cyclic nucleotide-gated ion channels modulate neurotransmission in the mammalian olfactory bulb. Neuron 37:639-647.

Murphy GJ, Darcy DP, Isaacson JS (2005) Intraglomerular inhibition: signaling mechanisms of an olfactory microcircuit. Nat Neurosci $8: 354-364$.

Nickell WT, Behbehani MM, Shipley MT (1994) Evidence for GABABmediated inhibition of transmission from the olfactory nerve to mitral cells in the rat olfactory bulb. Brain Res Bull 35:119-123.

Olsen SR, Wilson RI (2008) Lateral presynaptic inhibition mediates gain control in an olfactory circuit. Nature 452:956-960.

Puopolo M, Bean BP, Raviola E (2005) Spontaneous activity of isolated dopaminergic periglomerular cells of the main olfactory bulb. J Neurophysiol 94:3618-3627.
Spors H, Wachowiak M, Cohen LB, Friedrich RW (2006) Temporal dynamics and latency patterns of receptor neuron input to the olfactory bulb. J Neurosci 26:1247-1259.

Verhagen JV, Wesson DW, Netoff TI, White JA, Wachowiak M (2007) Sniffing controls an adaptive filter of sensory input to the olfactory bulb. Nat Neurosci 10:631-639.

Vucinic D, Cohen LB, Kosmidis EK (2005) Interglomerular centersurround inhibition shapes odorant-evoked input to the mouse olfactory bulb in vivo. J Neurophysiol 95:1881-1887.

Wachowiak M, Cohen LB (1999) Presynaptic inhibition of primary olfactory afferents mediated by different mechanisms in lobster and turtle J Neurosci 19:8808-8817.

Wachowiak M, Cohen LB (2001) Representation of odorants by receptor neuron input to the mouse olfactory bulb. Neuron 32:723-735.

Wachowiak M, Shipley MT (2006) Coding and synaptic processing of sensory information in the glomerular layer of the olfactory bulb. Semin Cell Dev Biol 17:411-423.

Wachowiak M, McGann JP, Heyward PM, Shao Z, Puche AC, Shipley MT (2005) Inhibition of olfactory receptor neuron input to olfactory bulb glomeruli mediated by suppression of presynaptic calcium influx. J Neurophysiol 94:2700-2712. 